
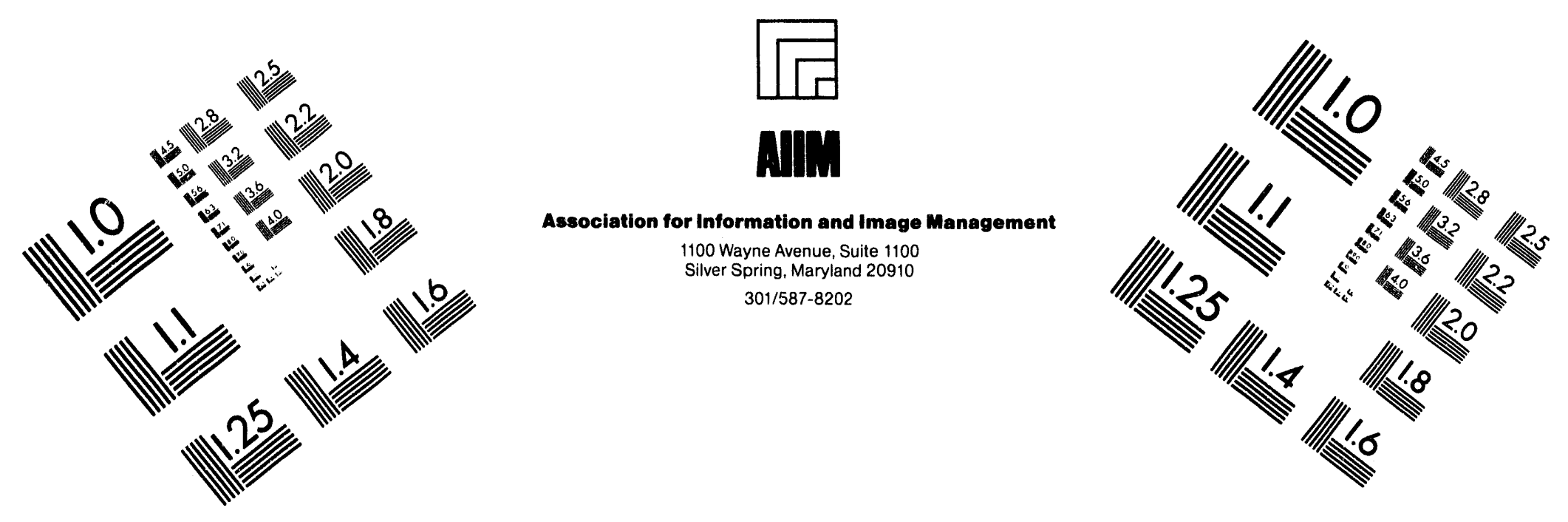

\title{
Centimeter
}

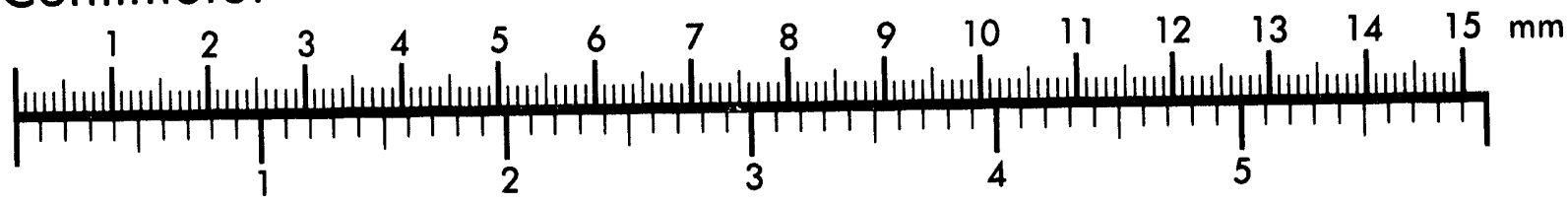
Inches
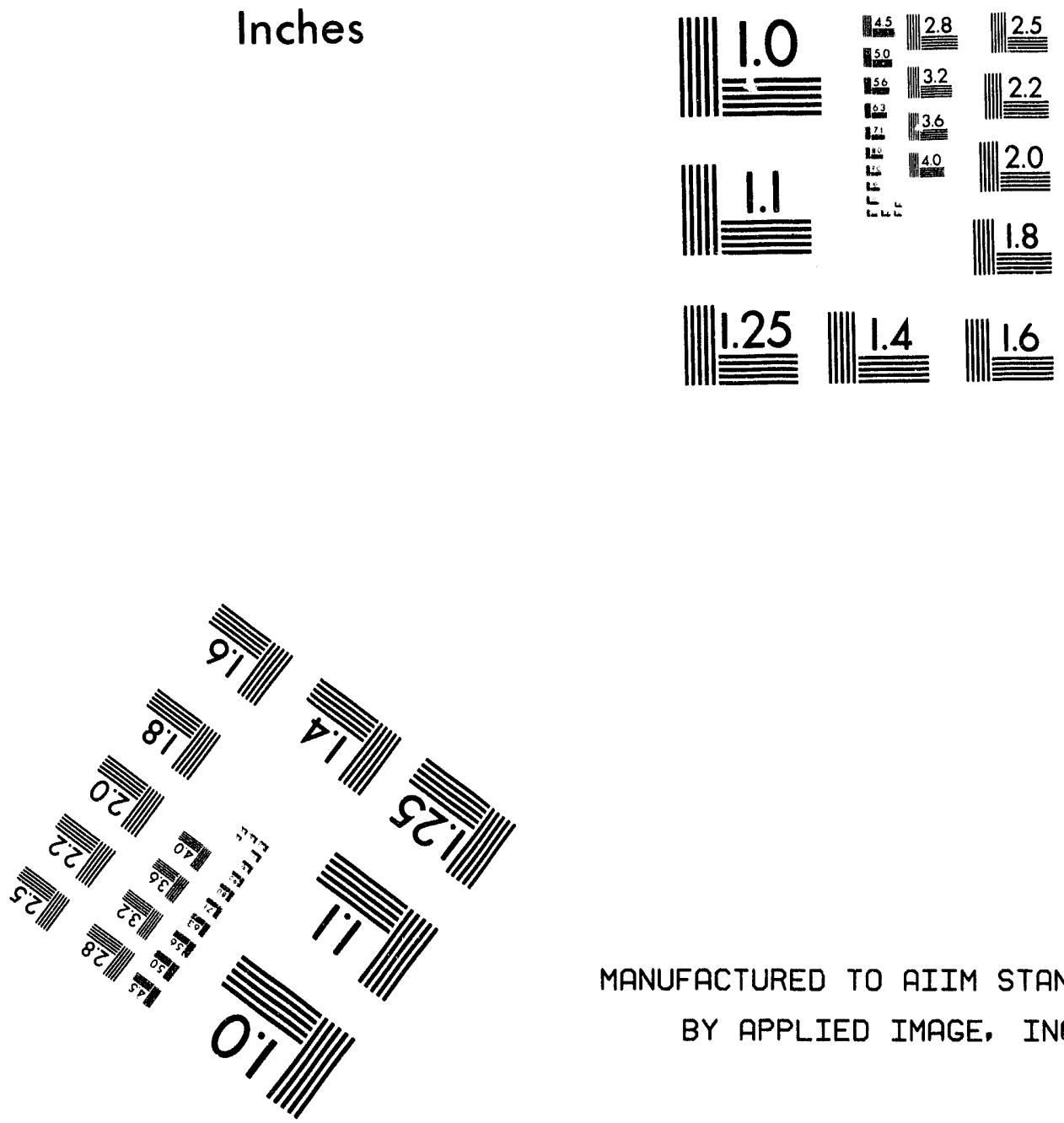

MANUFACTURED TO AIIM STANDARDS

BY APPLIED IMAGE, INC.

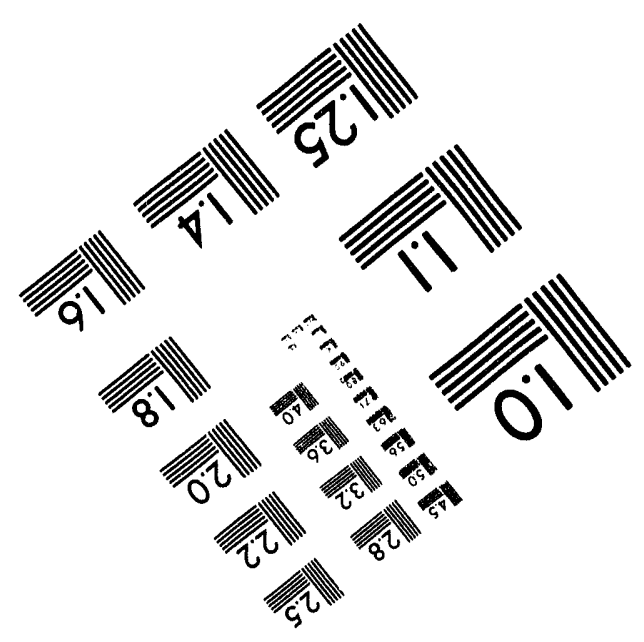



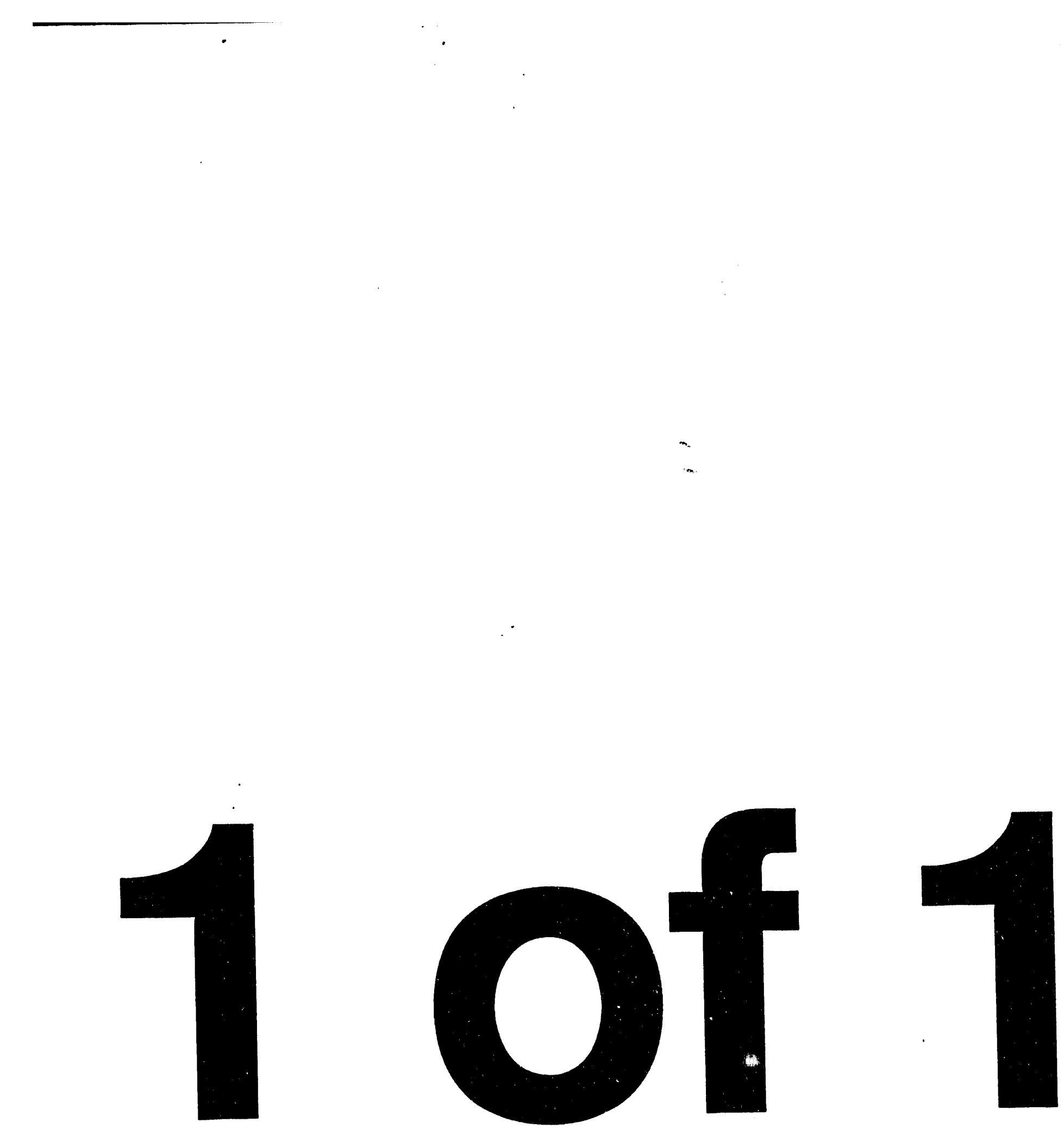


\title{
$12 / 509495(1)$
}

\section{Summary of Known Linear and Nonlinear Optical Properties of LiInS}

\author{
C. A. Ebbers
}

February 24, 1994

This is an informal report intended primarily for internal or limited external distribution. The opinions and conclusions stated are those of the author and may or may not be those of the Laboratory.

Work performed under the auspices of the U.S. Department of Energy by the Lawrence Livermore National Laboratory under Contract W-7405-Eng-48. 
TO: $\quad$ Stephan Velsko, L-495

FROM: Chris Ebbers

SUBJECT: Summary of known linear and nonlinear optical properties of LiInS 2

\section{Summary}

LiInS $_{2}$ is a potentially useful crystal for cascaded parametric frequency conversion in the mid-IR. It is nearly noncritically phasematched for $1.064 \mu \mathrm{m}$ pumped, degenerate $2.12 \mu \mathrm{m}$ generation and 2 micron pumped generation of 3-5 $\mu \mathrm{m}$ light. The nonlinear optical coefficients are $2 \mathrm{x}$ larger than those of KTP or KTA, while the transparency extends from $0.5-8 \mu \mathrm{m}$. LiInS 2 crystals are currently available in volumes up to $5 \mathrm{~mm}^{3}$. This memo provides a brief summary of the current literature concerning the growth and linear and nonlinear optical properties of LiInS 2 .

\section{Growth}

LiInS $_{2}$ is a congruently melting compound which crystallizes with point symmetry $\mathrm{mm} 2$ and is isostructural with $\mathrm{LiGaO}_{2}, \mathrm{LiGaS}_{2}, \mathrm{LiInSe}_{2}$, and $\mathrm{LiInTe}_{2}$. It is grown at temperatures around $880^{\circ} \mathrm{C}$ by directional solidification in graphite (or tantalum) crucibles. ${ }^{1-9}$ The starting components for the growth runs are typically metallic $\mathrm{Li}, \mathrm{S}$, and $\mathrm{In}_{2} \mathrm{~S}_{3}$. The initial reaction of the starting components is highly exothermic, perhaps similar to the growth of $\mathrm{ZnGeP}$. Growth is complicated by the high vapor pressure of the melt as well as the reactivity of molten $\mathrm{Li}$, which readily oxidizes, as well as attacks standard crucible materials such as Pt.

\section{General Properties of LiInS 2}

$\mathrm{LiInS}_{2}$ is a rarity among materials potentially useful for mid infrared nonlinear optics in that it is optically biaxial. Optically biaxial materials are of interest due to the possibility of thermally insensitive phasematching directions, that is, propagation directions in which the phasematching thermal bandwidth is very large. LiInS $_{2}$ is transparent from approximately $500 \mathrm{~nm}$ to $9 \mu \mathrm{m}(\alpha<$

AA/Ebbers $/ 002 / \mathrm{mmf}$

University of California

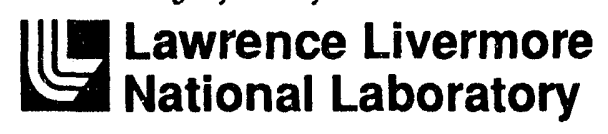


$10 \% / \mathrm{cm}$ ). Mention is explicitly made that the material does not appear to have the structural defects (high conductivity) associated with $\mathrm{AgGaS}_{2}$ type compounds. The resistivity has been measured in 3 different references to be $>10^{11} \Omega-\mathrm{m}$. No photoconductivity in the crystal is observed. Unfortunately, the small electro-optic coeffcients would make $\mathrm{LiInS}_{2}$ a poor choice as an electro-optic material. The material has a "high" hardness. Crystals are transparent (or slightly yellow), and are stable in air, water, toluene, etc. Crystals may be etched in $\mathrm{HNO}_{3}$ or bromine. The size of the crystals obtained in Ref. 10 is not mentioned, although a prism and 2 (thin) $5^{\circ}$ wedges were fabricated. Other references ${ }^{1-9}$ have obtained crystals $4 \times 4 \times 5 \mathrm{~mm}^{3}$. (Additional comment: I contacted G.D. Boyd. $10 \mathrm{He}$ recalls that the material was sufficient to cut a prism around $5 \mathrm{~mm}$ on a side).

\section{Linear and Nonlinear Optical Properties}

The linear and nonlinear optical properties of LiInS 2 have been measured in References 10-12. The refractive indices have been measured 10 from $450 \mathrm{~nm}$ to $11 \mu \mathrm{m}$. Using these values for the refractive index, we have obtained the best fit parameters of Table I to the 4 parameter Sellmeier equation (1). The $Z$ or 2 -fold axis is coincident with $n_{\gamma}, X$ is coincident with $n_{\beta}$, and $Y$ is coincident with $n_{\alpha}$, where $n_{\alpha}<n_{\beta}<n_{\gamma}$. By symmetry, nonlinear coupling in the principal planes vanishes for propagation down the $\mathrm{Z}$ axis and is significant only for Type II and Type III interactions. The birefringence of the $\gamma-\beta$ birefringence is small, thus phasematching in this principal plane will have a large angular acceptance (small angular sensitivity).

$$
\mathrm{n}^{2}=\mathrm{A}+\frac{\mathrm{B}}{\mathrm{C}+\lambda^{2}}+\mathrm{D} \lambda^{2}
$$

\begin{tabular}{|c|c|c|c|}
\hline \multicolumn{4}{|c|}{ Table I. Sellmeier parameters (1) for $\mathrm{LiInS}_{2}$} \\
\hline & $\alpha$ or $\mathrm{Y}$ & $\beta$ or $\mathrm{X}$ & $\gamma$ or $\mathrm{Z}$ or 2 fold axis \\
\hline A & 4.418222 & 4.559534 & 4.59206 \\
\hline B & 0.1254461 & 0.1403701 & 0.1410887 \\
\hline C & -0.0657432 & -0.069233 & -0.069287 \\
\hline D & -0.0028850 & -0.0028731 & -0.0030589 \\
\hline
\end{tabular}

The loci for a Type II, $1.064 \mu \mathrm{m}$ pumped OPO are displayed in Figure 1 for generation of signal between 3.5 and $2.4 \mu \mathrm{m}$. The noncritical wavelength for propagation down the $\beta$ dielectric axis is $2.29 \mu \mathrm{m}$ for Type II doubling. Thus, $\mathrm{LiInS}_{2}$ is nearly non-critically phasematched as a 1.064 $\mu \mathrm{m}$ pumped, Type II degenerate OPO down the $\beta$ dielectric axis. As displayed in Figure 2, $\mathrm{LiInS}_{2}$ is also non-critically phasematched for Type II generation of 3 and 5 micron light (signal 
and idler) from a 2.12 micron pump. The thermal behavior of the indices of refraction in $\mathrm{LinS}_{2}$ is currently not known. Angular sensitivity of phasematching in the $\beta-\gamma$ plane is $\sim 250 / \mathrm{cm}-\mathrm{rad}$ in the midsection of $\gamma-\alpha$ plane, and $\sim 860 / \mathrm{cm}$-rad in $\beta-\alpha$ plane within $20^{\circ}$ of $\beta$ axis.

The nonlinear optical coefficients of $\mathrm{LiInS}_{2}$ were measured at 10.6 and $1.06 \mu \mathrm{m}$ using the wedge technique, ${ }^{10}$ relative to $d_{14}$ of GaAs. Uncertainity in the value of $d_{14}$ of $\mathrm{GaAs}$ ranges from 90 $134 \mathrm{pm} / \mathrm{V} \cdot{ }^{10,15}$ Using the value $\mathrm{d}_{14} \sim 134 \mathrm{pm} / \mathrm{V}$ gives for $\mathrm{LiInS}_{2}$ :

$$
\begin{aligned}
& \mathrm{d}_{m \gamma}=18 \mathrm{pm} / \mathrm{V} \\
& \mathrm{d}_{\gamma \beta \beta}=15 \mathrm{pm} / \mathrm{V} \\
& \mathrm{d}_{y \alpha \alpha}=9.7 \mathrm{pm} / \mathrm{V} \text { at } 10.6 \mu \mathrm{m}
\end{aligned}
$$

This may be compared to $\mathrm{d}_{14} \sim 111 \mathrm{pm} / \mathrm{V}$ for $\mathrm{ZnGeP}_{2}$. However, for a noncritically pumped 1.06 micron to 2.12 micron application, $\mathrm{LiInS}_{2}$ should be compared with $\mathrm{LiNbO}_{3}, \mathrm{KTP}$, and KTA. The effective nonlinearity in $\mathrm{LinS}_{2}$ is approximately $2 \mathrm{x}$ larger than that of KTA, KTP or $\mathrm{LiNbO}_{3}$.

\section{Availability}

LiInS $_{2}$ is currently available in $\sim 5 \mathrm{~mm}^{3}$ volumes from Japanese and former Soviet Union (FSU) sources. I have contacted Z. Z. Kish (Ref. 5, 7, 8, 9, and 12) formerly of Uzhgorod State University, now located in Canada. He indicated that only crypto-crystalline material is available from his institute, useful for semiconductor research. However, K. Kuriyama of Hosei University (Ref. 2-4) has indicated that he is interested in collaborating on research involving $\mathrm{LiInS}_{2}$, and has pieces a few $\mathrm{mm}^{\wedge} 3$ in volume. We are also currently pursuing alternative sources in the Russia and United States.

\section{References}

1. R. Hoppe, W. Lidecke, F-C. Frorath, "Zur Kenntnis von $\mathrm{NaInS}_{2}$ und NaInSe2," Z. Anorg. allg. Chemie. 309, pp. 49-54 (1961).

2. T. Kamijoh, K. Kuriyama, "Single crystal growth and characterization of LiInSe,", J. Cryst. Growth 51, pp. 6-10 (1981).

3. K. Kuriyama, T. Kamijoh "Single crystal growth and characterization of $\mathrm{Li}_{2} \mathrm{ZnGe}_{2}$," J. Cryst. Growth 46, pp. 151-153 (1979).

4. T. Kamijoh, K. Kuriyama, "Single crystal growth of LiInS 2 ," J. Cryst. Growth 46, pp. 801803 (1979). 
5. Z. Z. Kish, V. B. Lazarev, E. Yu. Peresh, E. E. Semrad, I. S. Shaplygin, "Phase Equilibria in $\mathrm{A}_{2} \mathrm{CVI}^{\mathrm{VI}} \mathrm{In}_{2} \mathrm{C}_{3} \mathrm{VI}$ Systems," Shurnal Neorganicheskoi Khimii, 30, pp. 1499-1501 (1985).

6. S. K. Kovach, E. E. Semrad, Yu. V. Voroshilov, V. S. Gerasimenko, V. Yu. Slivka, N. P. Stasyuk, "Preparation and principal physicochemical properties of alkali metal indates and thioindates," Neorganicheski Materialy, 14, \#12, pp. 2172-2176 (1978).

7. Z. Z. Kish, E. Yu. Peresh, V. B. Lazarev, E. E. Semrad, "Systematics and the rules of variations in the properties of $\mathrm{A}^{\mathrm{I}} \mathrm{B}^{\mathrm{III}} \mathrm{C}_{2} \mathrm{VI}$ Type Compounds," Neorganicheski Materialy, 23, \#5, pp. 777-784 (1987).

8. Z. Z. Kish, A. S. Kanishcheva, Yu. N. Mikhailov, V. B. Laxarev, E. E. Semrad, E. Yu. Peresh, "Synthesis and crystal structure of LiInS2," Doklady Akademii Nauk SSSR, 280, pp. 398-401 (1985).

9. Z. Z. Kish, V. B. Lazarev, E. E. Semrad, E. Yu. Peresh, I. V. Galagovets, "Some properties of single crystals of LiInS $_{2}$ and $\mathrm{NaInS}_{2}$," Neorganicheski Materialy, 20 \#12, pp. 750-752 (1984).

10. G. D. Boyd, H. M. Kasper, J. H. McFee, "Linear and nonlinear optical properties of LiInS2,"J. Appl. Phys. 44, pp 2809-2812 (1973).

11. T. J. Negran, H. M. Kasper, A. M. Glass, "Pyroelectric and electro-optic effects in LiInS 2 and LiInSe," Mat. Res. Bull. 8, pp. 743-748 (1973).

12. Z. Z. Kish, E. Yu. Peresh, V. B. Lazarev, E. E. Semrad, "Properties of $\mathrm{LiGaS}_{2}$ Single Crystals," Neorganicheski Materialy, 25, \#12, pp. 1959-1962 (1989).

13. R. C. Miller, W. A. Nordland, E. E. Kolb, W. L. Bond, "Nonlinear Optical Properties of LiGaO2,"I. Appl. Phys. 41, pp. 3008-3011 (1970).

14. P. V. Lenzo, E. G. Spencer, J. P. Remeika, "Some Optical Properties of $\mathrm{LiGaO}_{2}$," Appl. Optics 4, pp. 1036-1037 (1965).

15. Landolt-Bornstein III/11, "Elastic, Piezoelectric, and Related Constants of Crystals," (Springer Verlag New York 1979), p.673.

Attachments (2 Figures)

cc: Bill Krupke 


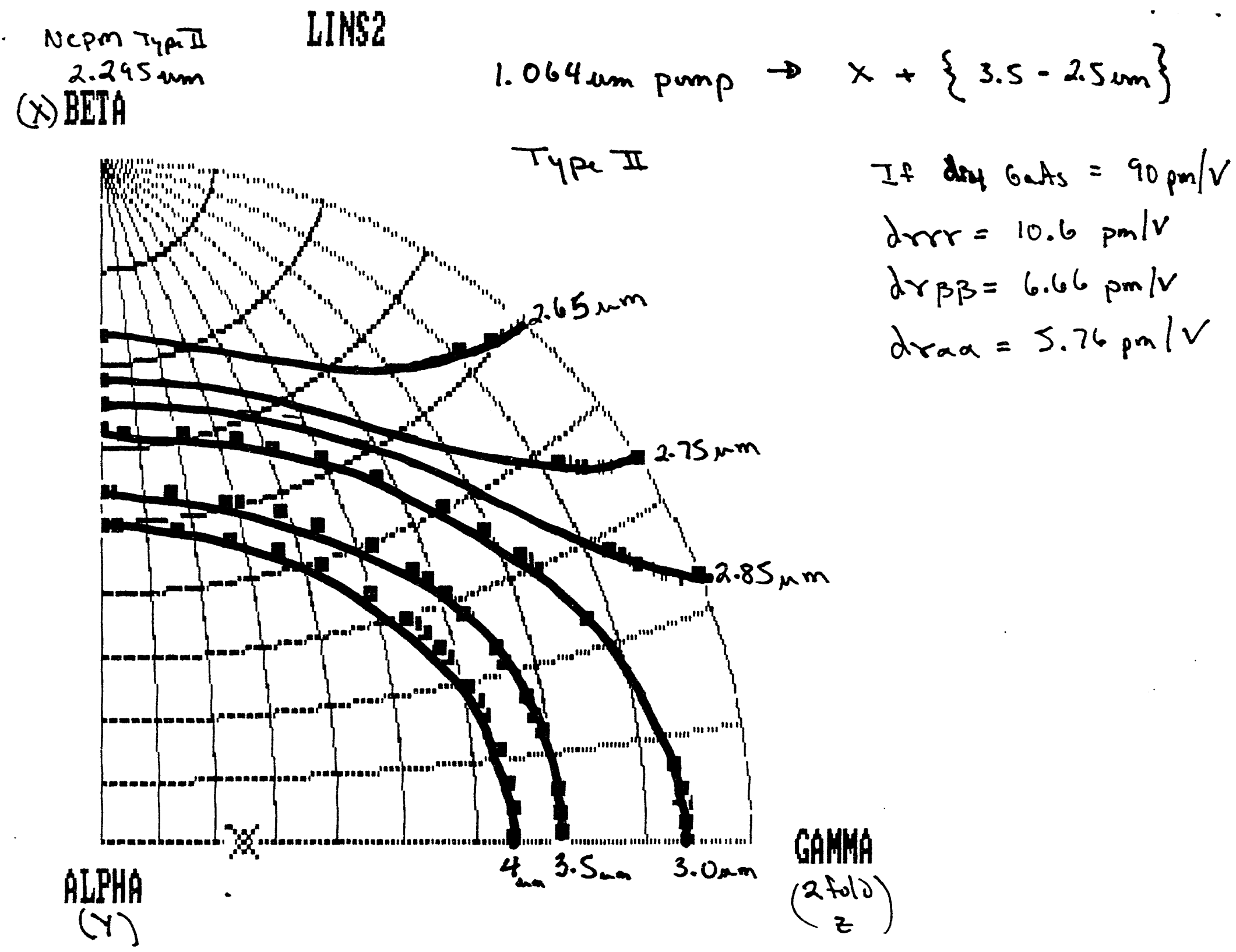


LING

$X$, BETA

$$
2.12 \text { um pump } \rightarrow \text { (idler, signal) um }
$$

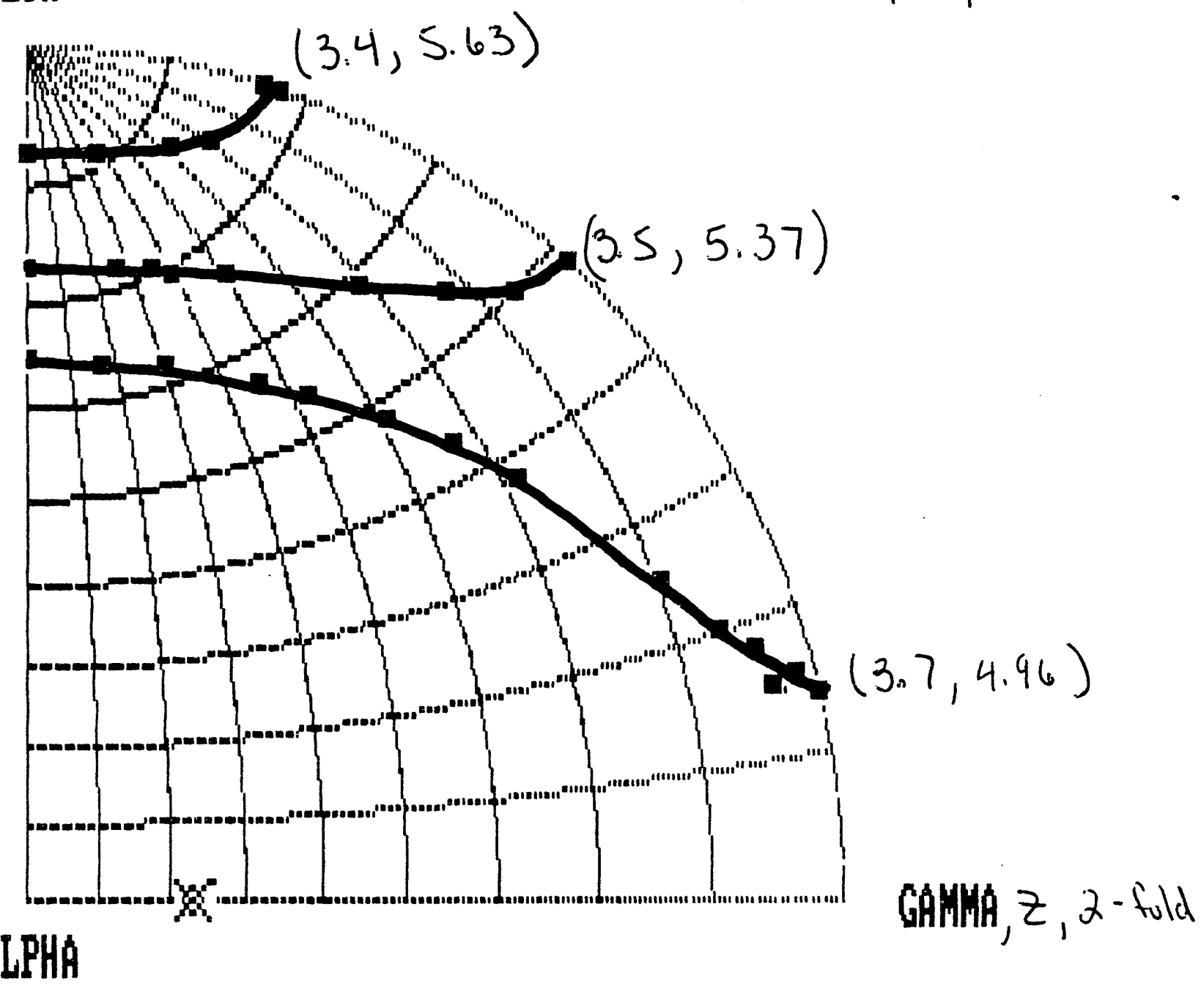

Y, ALPHA

Figure 2. Phasematching locus vs. signal generation for Type II, 2.12 micron pumped optical parametric interaction in LiInS2. 

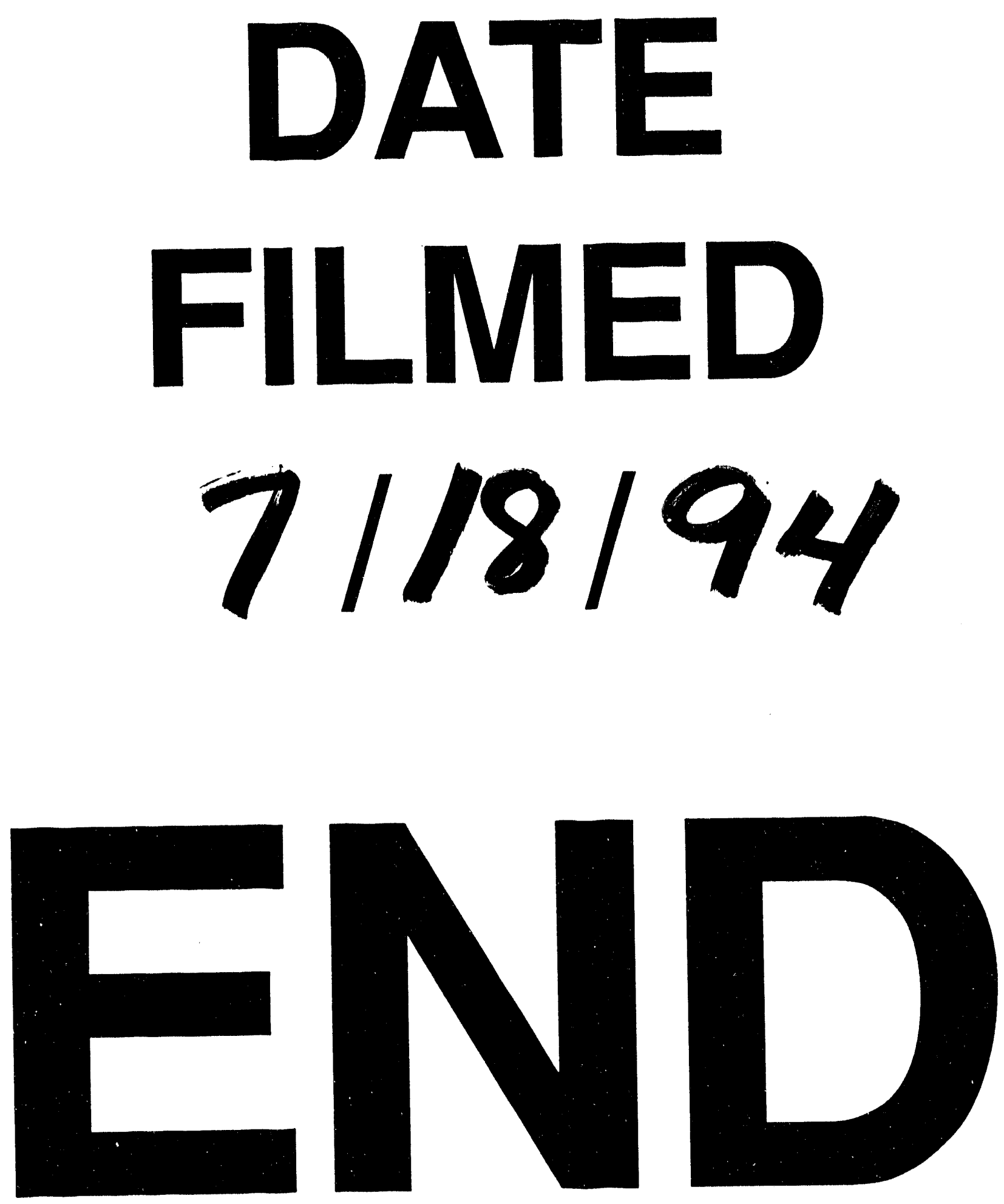

IV 

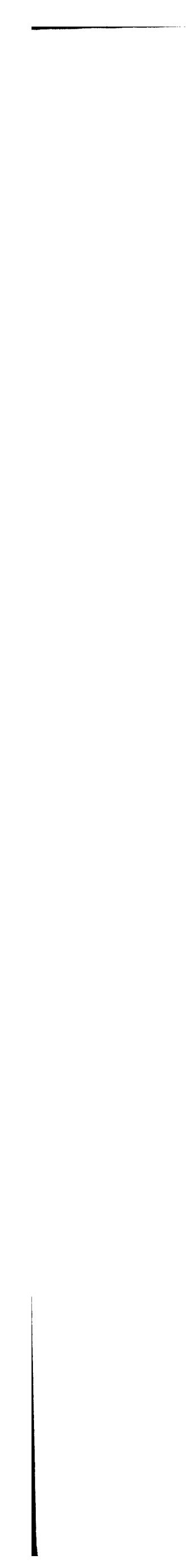